\title{
Tuberculosis ileocecal: a propósito de un caso
}

\section{lleocecal tuberculosis: A case report}

\author{
Carlos Mauricio Martínez-Montalvo, ${ }^{1{ }^{*}}$ (1) Alejandro Botello-Gil, ${ }^{2}$ (1) Laura Melisa Herrera, ${ }^{3}$ (1) Sofía Fernanda Leal-Bernal, ${ }^{4}$ (1) \\ Margareth Elizabeth Guerrero. ${ }^{5}$
}

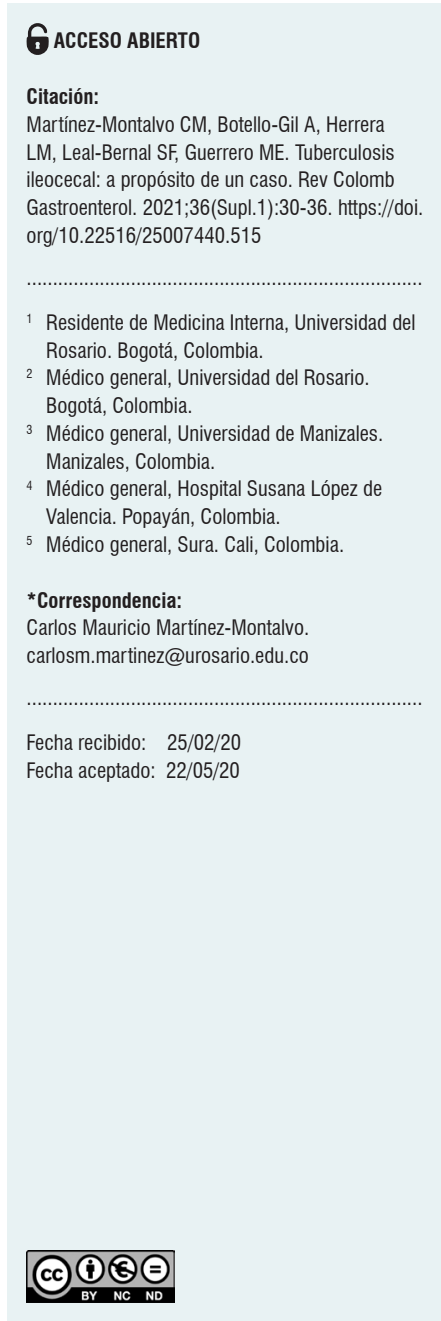

\begin{abstract}
Resumen
La tuberculosis es una enfermedad de importancia en la salud pública a nivel mundial, con una alta incidencia a nivel del territorio colombiano. Principalmente, afecta el parénquima pulmonar; sin embargo, en un porcentaje elevado de casos se diagnostica en su forma extrapulmonar y el tracto gastrointestinal es uno de los sitios más frecuentes. Así mismo, la región ileocecal y el íleon terminal son las regiones con más predilección por la bacteria Mycobaterium tuberculosis. Las manifestaciones en esta rara presentación de la enfermedad están dadas por dolor abdominal y sensación de masa principalmente, lesiones ulcerosas en la mucosa intestinal y hallazgos histológicos correspondientes a granulomas caseificantes de gran tamaño y de morfología confluente, que se diferencian de otras entidades como la enfermedad de Crohn. La búsqueda de la enfermedad dentro del tracto gastrointestinal se realiza con ayuda de métodos invasivos como la colonoscopia y de ayudas diagnósticas de laboratorio como cultivos, tinciones o reacción en cadena de la polimerasa (PCR). Dada la complejidad en el diagnóstico de esta forma de tuberculosis, el conocimiento y la manera en que se aborda un paciente con un cuadro sugestivo de esta enfermedad son factores importantes para establecer el manejo terapéutico oportuno. Se comparte un caso inusual de tuberculosis ileocecal como manifestación de síndrome febril prolongado con desenlace fatal.
\end{abstract}

\section{Palabras clave}

Tuberculosis ileocecal, tuberculosis intestinal, tuberculosis extrapulmonar, PCR para Mycobacterium tuberculosis, infartos esplénicos, tuberculosis ósea.

\begin{abstract}
Tuberculosis is a disease of public health importance worldwide with a high incidence in Colombia. It mainly affects the lung parenchyma. However, in a large number of cases, it is diagnosed in its extrapulmonary form, with the gastrointestinal tract being one of the most frequent sites. Mycobacterium tuberculosis has a strong predilection for the ileocecal region and the terminal ileum. Manifestations of this rare form of the disease are abdominal pain and mass sensation mainly, as well as ulcerative lesions in the intestinal mucosa and histological findings corresponding to large caseating granulomas of confluent morphology, which distinguish it from other entities such as Crohn's disease. Invasive procedures, such as colonoscopy, and diagnostic laboratory aids, such as cultures, stains, and PCR, are used to find the disease in the gastrointestinal tract. Given the difficulty of diagnosing this type of tuberculosis, knowledge and how a patient with symptoms suggestive of the disease is approached are critical factors for establishing timely treatment. The following is an unusual case of ileocecal TB as a manifestation of prolonged febrile illness with a fatal outcome.
\end{abstract}

\section{Keywords}

lleocecal tuberculosis; Intestinal tuberculosis; Extrapulmonary tuberculosis; PCR for Mycobacterium tuberculosis; Splenic infarction; Bone tuberculosis. 


\section{INTRODUCCIÓN}

La tuberculosis es una de las principales enfermedades con mayor carga social y económica a nivel mundial. Para 2017, se estimó una incidencia global de 10 millones de casos, con un mayor porcentaje de esta en las regiones del sureste de Asia y África (1). Así mismo, cerca de 1,6 millones de personas murieron para el mismo período. En América Latina se registró una incidencia de 263000 casos y cerca de 20000 muertes (1). En Colombia, la tuberculosis sigue siendo una patología prevalente, con una incidencia de 26,5 casos por cada 100000 habitantes y un total de 14480 casos nuevos reportados para 2017 (2), con un comportamiento que afecta principalmente a los mayores de 65 años, una mayor prevalencia en el sexo masculino y una forma de presentación principalmente pulmonar (83,3\%) (2).

Los factores de riesgo para el desarrollo de la enfermedad se clasifican en dos grandes grupos: aquellas personas que han estado en contacto con la bacteria o que hayan tenido la enfermedad (inmigrantes, indigentes, usuarios de fármacos IV, trabajadores de la salud) y aquellos con un sistema inmunológico comprometido (ancianos, virus de la inmunodeficiencia humana $[\mathrm{VIH}]$, silicosis, diabetes mellitus $[\mathrm{DM}]$, enfermedad renal crónica [ERC], desnutrición, entre otras) (3). Dentro de los factores de riesgo mencionados, la coinfección con VIH es el más importante, dado que al menos el $40 \%$ de los pacientes con el virus muere a causa de la tuberculosis y, aproximadamente, en la mitad de los casos la enfermedad no se diagnostica sino hasta el momento de la autopsia (4).

A pesar de que la tuberculosis afecta con mayor frecuencia el pulmón, es más frecuente encontrar pacientes a quienes se les realiza el diagnóstico en un sitio extrapulmonar, lo que se explica por la diseminación hematógena o linfática del bacilo de Mycobacterium tuberculosis dentro del cuerpo y cuya presentación clínica se puede evidenciar en años posteriores. Los factores de riesgo para el desarrollo de tuberculosis extrapulmonar son la infección por VIH, uso de antagonistas del factor de necrosis tumoral (TNF), corticoesteroides, malignidad, sexo femenino y comorbilidades asociadas como DM o ERC (5). Su prevalencia varía del $10 \%$ al $60 \%$ dependiendo del lugar geográfico. De esta forma, en 2016 se reportó en los Estados Unidos una prevalencia del $20 \%$ en la forma extrapulmonar y del $10 \%$ para la forma de presentación mixta; es decir, tanto pulmonar como extrapulmonar (6). En Colombia, del total de casos nuevos registrados de tuberculosis para 2017, cerca del $17 \%$ era de presentación extrapulmonar y la mayoría de los casos tenía uno de los factores de riesgo previamente mencionados (2).

Los sitios extrapulmonares con mayor afectación son la región genitourinaria, linfática, ósea, pleural y, finalmente, la gastrointestinal, que ocupa el quinto o sexto lugar en orden de frecuencia dependiendo de la epidemiologia local (5). Además, dentro del tracto gastrointestinal, la región más afectada es la ileocecal y el íleon terminal, correspondiente al $67 \%$ de los casos (7). Así mismo, identificar el compromiso del tracto gastrointestinal representa un reto diagnóstico dado que la enfermedad se presenta con una sintomatología muy variada e inespecífica, que puede estar acompañada en ocasiones de complicaciones graves como perforación, hemorragia y obstrucción. En segundo lugar, simula otras entidades como la colitis ulcerosa, linfoma, amebiasis o enfermedad de Crohn (7). Su diagnóstico requiere de herramientas clínicas y de laboratorio, y el cultivo y las técnicas moleculares son las que poseen mayor sensibilidad y especificidad. Finalmente, su tratamiento puede ser médico o quirúrgico dependiendo de la presentación clínica.

Se presenta un caso de tuberculosis intestinal en un hombre de 75 años, con factores de riesgo para desarrollar esta enfermedad, que debido a la presentación y localización de la enfermedad fue complejo su abordaje desde el inicio de la hospitalización. Así mismo, se describen las herramientas y diagnósticos diferenciales que se tuvieron en cuenta para poder llegar al diagnóstico y tratamiento adecuado y de cómo, a pesar de este, se tuvo un desenlace mortal.

\section{CASO CLÍNICO}

Se trata de un hombre de 75 años de Bogotá, pensionado, quien se desenvolvió como celador durante más de 50 años. Trabajó adicionalmente en agricultura por 4 años en un área rural cercana a la ciudad. Tenía antecedentes de hábito tabáquico por más de 3 décadas (índice paquetes año[IPA] 12) y exposición al humo de leña, hipertensión arterial, ERC con una tasa de filtración glomerular (TFG) de $49 \mathrm{~mL} / \mathrm{min} / 1,73 \mathrm{~m}^{2}$ por CKD-EPI (Chronic Kidney Disease Epidemiology Collaboration), cáncer de próstata con requerimiento de prostatectomía y posterior terapia antiandrogénica con análogos de la hormona liberadora de gonadotropina $(\mathrm{GnRH})$ con valores normales del antígeno prostático en el seguimiento por 3 años. Además, tenía anemia en estudio y perfil carencial en el que se documentó ferropenia, que fue manejada de manera ambulatoria con eritropoyetina y suplencia de vitamina $B_{12}$.

Ingresó por un cuadro clínico de 9 meses de evolución consistente en pérdida de peso de aproximadamente $12 \mathrm{~kg}$, sudoración nocturna, astenia, adinamia y tos ocasionalmente productiva en el último mes. Adicionalmente, manifestó tener deposiciones diarreicas sin moco ni sangre, aproximadamente de 4 a 5 deposiciones al día durante 4 días antes del ingreso, la cual resolvió por sí mismo con hidratación y medidas generales. $\mathrm{Al}$ ingreso se documentó fiebre en $38,3^{\circ} \mathrm{C}$, palidez generalizada y taquicardia; y los 
exámenes de laboratorio iniciales documentaron leucopenia, anemia de volúmenes bajos en criterios de transfusión, trombocitopenia, hiponatremia leve hipovolémica hipoosmolar, hipomagnesemia e hipoalbuminemia (Figura 1 y Tabla 1). En el estudio de tomografía de tórax se obtuvieron hallazgos compatibles con silicoantracosis e imágenes hipodensas en las vértebras de carácter inespecífico (Figura 2).

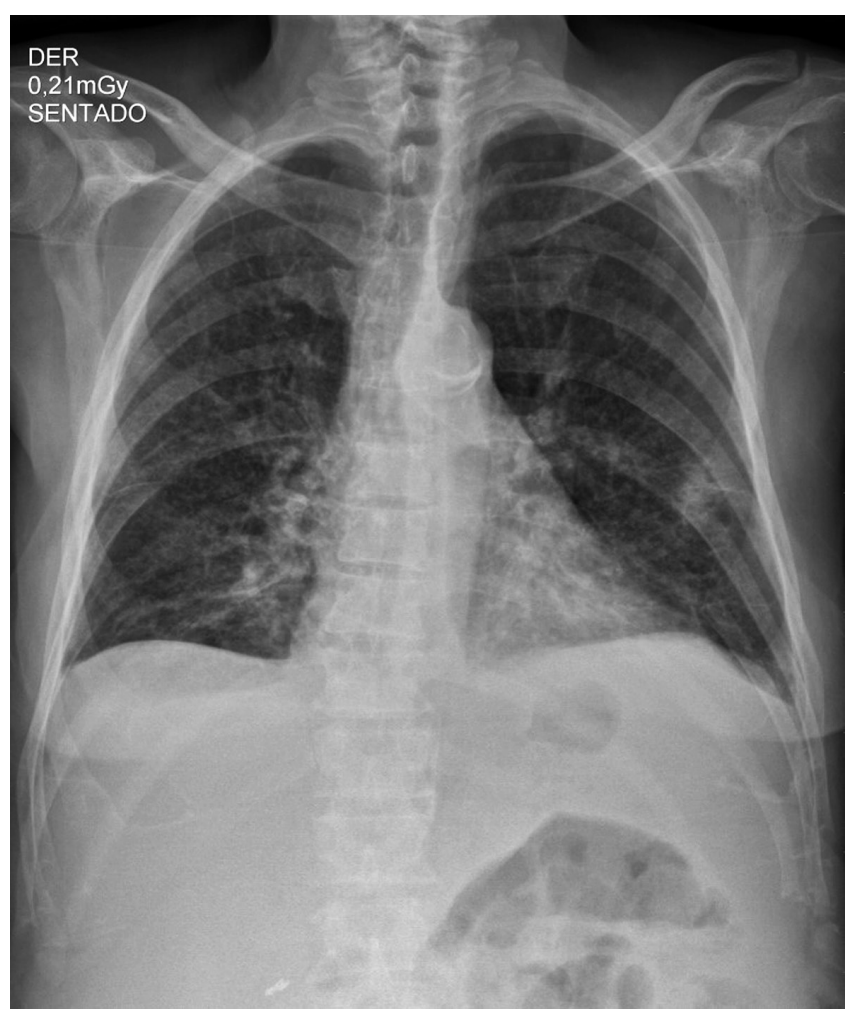

Figura 1. Radiografía anteroposterior $(\mathrm{AP})$ de tórax que muestra opacidades intersticiales reticulares gruesas en ambos campos pulmonares y ángulos costofrénicos libres.

Ante la persistencia de picos febriles con la clínica del paciente, se decidió realizar el cubrimiento antibiótico con cefepima, con un posterior estudio de baciloscopias seriadas negativas. Debido a la alteración de las líneas celulares hematológicas, se ampliaron los estudios con frotis de sangre periférica normal, electroforesis de proteínas con un componente policlonal, citometría de flujo negativa para hemoglobinuria paroxística nocturna y biopsia de la médula ósea negativa para malignidad, con una hipocelularidad del $10 \%$, esperada para la edad. Se descartó un compromiso medular y se inició el aporte de hierro intravenoso. En el estudio de síndrome febril, estudios adicionales resultaron con un perfil hepático normal, ecografía de abdomen con hallazgos de hepatomegalia y esplenomegalia con múltiples lesiones focales correspondientes a infartos, hemocultivos negativos, antígenos febriles negativos, cultivo de esputo
Tabla 1. Paraclínicos al ingreso y durante la hospitalización del paciente

\begin{tabular}{|c|c|c|c|c|}
\hline Paraclínico & Al ingreso & $\begin{array}{c}\text { A la } \\
\text { semana } 1\end{array}$ & $\begin{array}{c}\text { A la } \\
\text { semana } 2\end{array}$ & $\begin{array}{c}\text { A la } \\
\text { semana } 3\end{array}$ \\
\hline Leucocitosis $(/ \mu \mathrm{L})$ & 2720 & 3690 & 2040 & 2530 \\
\hline Neutrófilos $(/ \mu \mathrm{L})$ & 2067 & 2940 & 1428 & 2049 \\
\hline Linfocitos $(/ \mu \mathrm{L})$ & 260 & 350 & 208 & 254 \\
\hline Hematocrito (\%) & 23 & 28,9 & 23,2 & 24,5 \\
\hline Hemoglobina (g/dL) & 6,9 & 9,5 & 7,1 & 7,7 \\
\hline Plaquetas (/ $/ \mu \mathrm{L})$ & 78000 & 92000 & 58000 & 50000 \\
\hline Creatinina (mg/dL) & 1,4 & 1,06 & 1,02 & 0,97 \\
\hline BUN (mg/dL) & 28,8 & 30,8 & 31,7 & 35,3 \\
\hline $\begin{array}{l}\text { Bilirrubinas totales } \\
\text { (mg/dL) }\end{array}$ & 0,52 & & & 1,06 \\
\hline $\begin{array}{l}\text { Bilirrubina directa } \\
\text { (mg/dL) }\end{array}$ & 0,30 & & & 0,85 \\
\hline $\begin{array}{l}\text { Bilirrubina indirecta } \\
\text { (mg/dL) }\end{array}$ & 0,22 & & & 0,21 \\
\hline Albúmina (g/dL) & 2,3 & & & 2 \\
\hline $\begin{array}{l}\text { Fosfatasa alcalina } \\
\text { (UI/L) }\end{array}$ & 142 & & & 138 \\
\hline Amilasa (UI/L) & 24 & & & 27 \\
\hline AST (UI/L) & 31 & & & 28 \\
\hline ALT (UI/L) & 30 & & & 21 \\
\hline $\mathrm{TP}$ & 16,4 & & & 16,1 \\
\hline INR & 1,06 & & & 1,04 \\
\hline TTP & 33 & & & 48,5 \\
\hline Sodio (mEq/L) & 126 & 129 & 135 & 130 \\
\hline Potasio (mEq/L) & 4,2 & 3,07 & 5,03 & 4,4 \\
\hline Cloro (mEq/L) & 94 & 99 & 101 & 99 \\
\hline Calcio (mEq/L) & 8,1 & 9,2 & 9,3 & 10,3 \\
\hline Magnesio (mEq/L) & 1,23 & 1,41 & 2,24 & 1,5 \\
\hline $\mathrm{VIH}$ & Negativo & & & \\
\hline VDRL & No reactivo & & & \\
\hline Serología hepatitis C & Negativo & & & \\
\hline Serología hepatitis B & Negativo & & & \\
\hline Vitamina $B_{12}$ & $>2000$ & & & \\
\hline Ácido fólico & 19,2 & & & \\
\hline Antígeno prostático & 0,463 & & & \\
\hline Antigenuria & & & Negativo & \\
\hline Acs. histoplasma & & & Negativo & \\
\hline Factor reumatoideo & & & 10,4 & \\
\hline ANA & & & Negativo & \\
\hline ENA & & & Negativo & \\
\hline Ro & & & 2,9 & \\
\hline La & & & 3,6 & \\
\hline Sm & & & 12,6 & \\
\hline RNP & & & 2,0 & \\
\hline Acs. anti-ADN & & & $\begin{array}{l}\text { Positivo } \\
1 / 40\end{array}$ & \\
\hline
\end{tabular}

Acs.: anticuerpos; ALT: alanina-aminotransferasa; ANA: anticuerpos antinucleares; AST: aspartato-aminotransferasa; BUN: nitrógeno ureico sanguíneo; ENA: antígenos nucleares extraíbles; INR: índice internacional normalizado; RNP: ribonucleproteina; TTP: tiempo de tromboplastina parcial; TP: tiempo de protrombina; VDRL: prueba de la Venereal Disease Research Laboratory. 


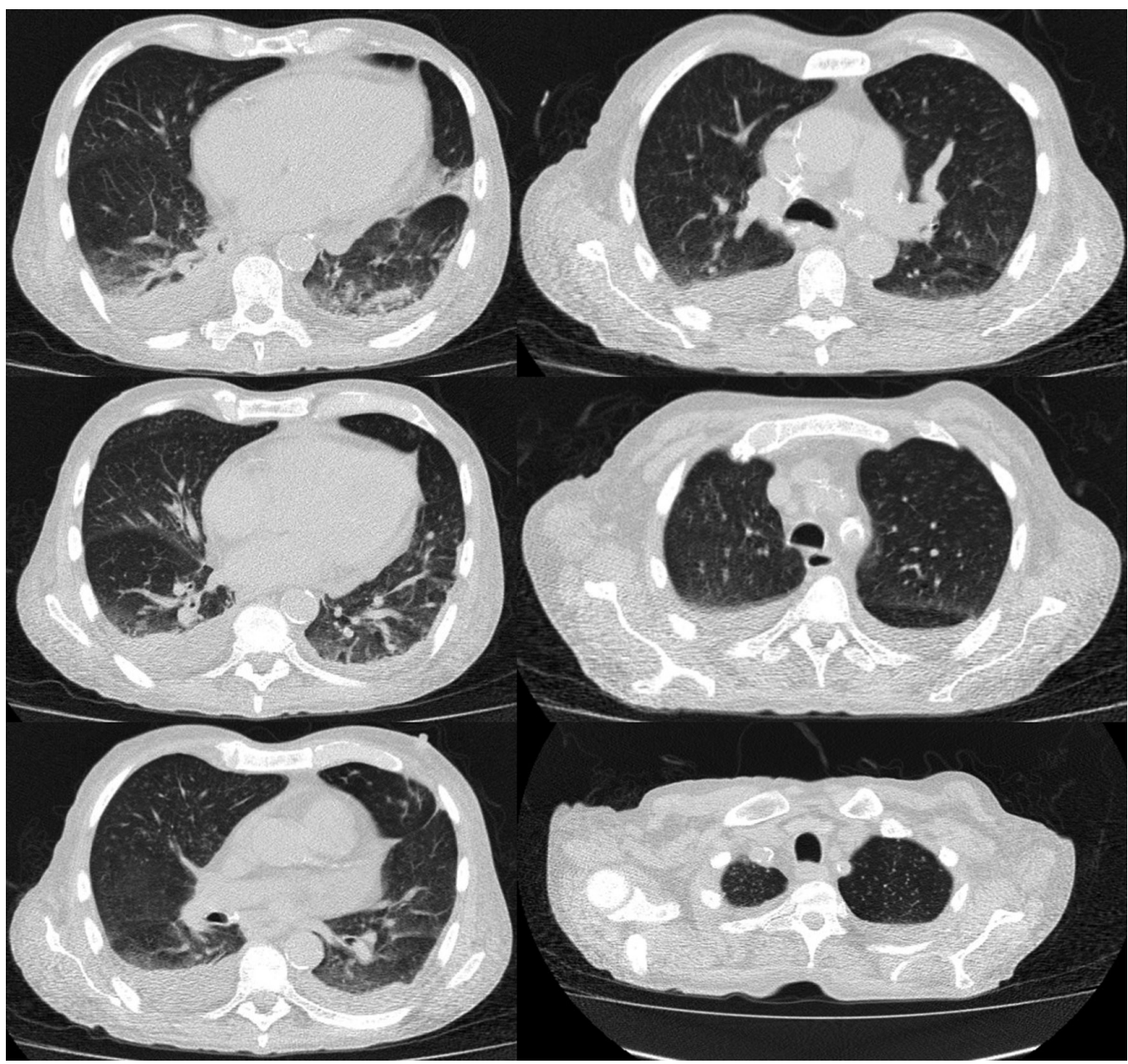

Figura 2. Tomografía axial computarizada de alta resolución (TACAR) de tórax que evidencia silicoantracosis, atelectasia de lóbulos inferiores y alteración en la densidad de cuerpos vertebrales y esternón. negativo, antígeno prostático normal y ecografía de tiroides sin alteraciones. Se ampliaron los estudios con tomografía de abdomen contrastado con un único hallazgo de engrosamiento de la mucosa ileocecal y las lesiones esplénicas ya documentadas (Figura 3). Se descartó una endocarditis por ecocardiograma transesofágico.

En la resonancia contrastada de la columna vertebral total se hallaron lesiones líticas en los cuerpos vertebrales L2, L3 y L4, y hueso ilíaco derecho con signos de reconversión medular (Figura 4). Durante la vigilancia clínica con cubrimiento antibiótico, se evidenció el deterioro clínico progresivo. Se realizó una colonoscopia en la que se evidenció una úlcera en la válvula ileocecal y el ciego, a la cual se le tomó una biopsia para realizar tinciones para hongos y reacción en cadena de la polimerasa (PCR) para tuberculosis. Ante el deterioro clínico con los hallazgos de múltiples órganos, se indicó el manejo con anfotericina B ante la sospecha de histoplasmosis, pero con niveles de galactomanano negativo, por lo cual se suspende al día 4 de manejo.

A pesar de no referir sintomatología relacionada con autoinmunidad, pero con presencia de síndrome febril prolongado, se solicitaron estudios de autoinmunidad con factor reumatoideo negativo, ENA negativos, anti-ADN negativo y ANA positivos para dilución 1/40.

Se presentó deterioro clínico con somnolencia, anasarca y aumento de la fiebre de características vespertinas; entró en insuficiencia ventilatoria y compromiso multiorgánico. Se recibió un reporte positivo de PCR para tuberculosis tomada de la biopsia de la úlcera ileocecal. Inmediatamente se inició el manejo con el esquema antibiótico tetraconjugado con pirazinamida, etambutol, rifampicina e isoniazida. A pesar del manejo instaurado, el paciente desarrolló 


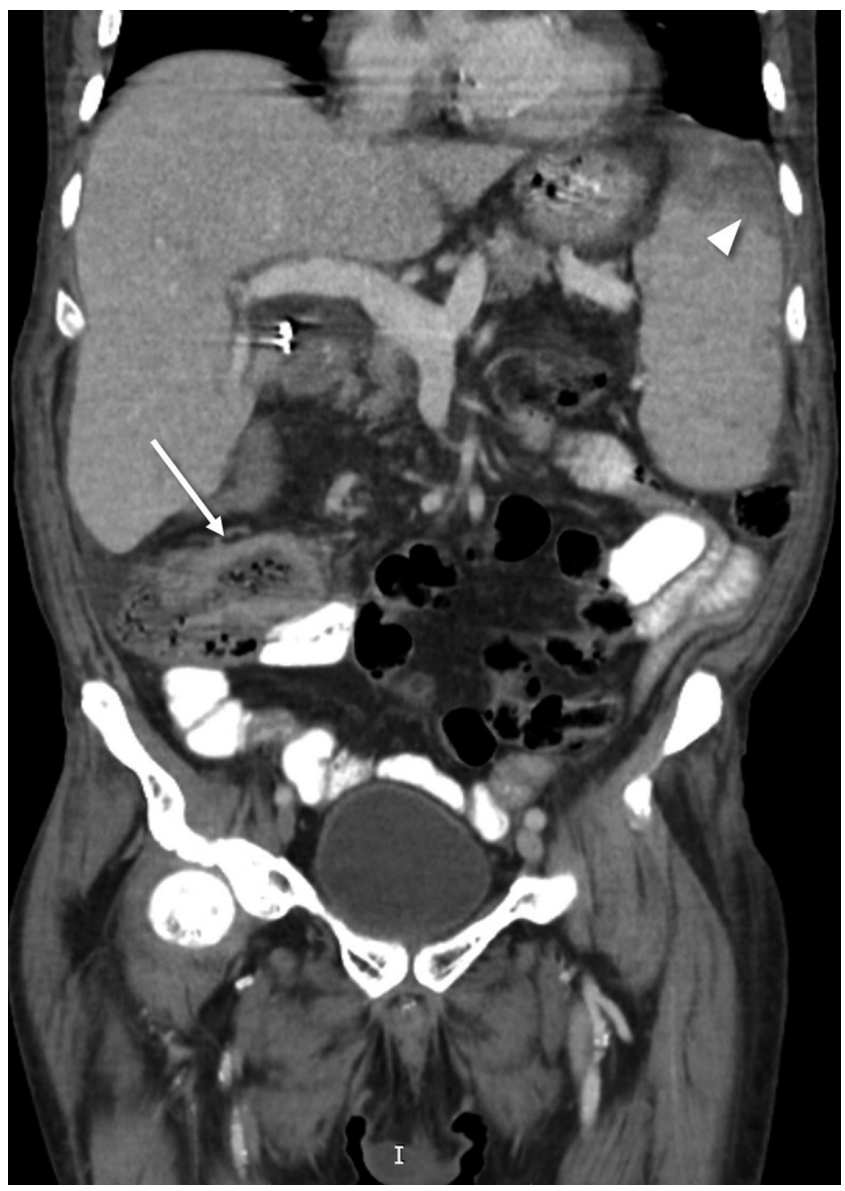

Figura 3. Tomografía de abdomen que evidencia engrosamiento de la pared del íleon distal (flecha blanca) e imágenes hipodensas subcapsulares correspondientes a infartos (cabeza de flecha).

choque séptico y distributivo, trastorno de la oxigenación grave y, finalmente, falleció después de 3 días de haber iniciado el esquema antituberculoso.

\section{DISCUSIÓN}

La tuberculosis extrapulmonar es una forma de presentación inusual de la enfermedad. Representa del $20 \%$ al $25 \%$ de los casos de tuberculosis (8). Los factores de riesgo descritos son la infección por VIH, uso de antagonistas del factor de necrosis tumoral (TNF), corticoides, malignidad, DM o ERC (5). En el mecanismo fisiopatológico se describe diseminación sanguínea o linfática, con distribución a cualquier sitio del cuerpo; la afectación del tracto gastrointestinal (TGI) tiene una prevalencia entre el $3 \%$ y el $5 \%$ dentro de los casos extrapulmonares de tubercu-

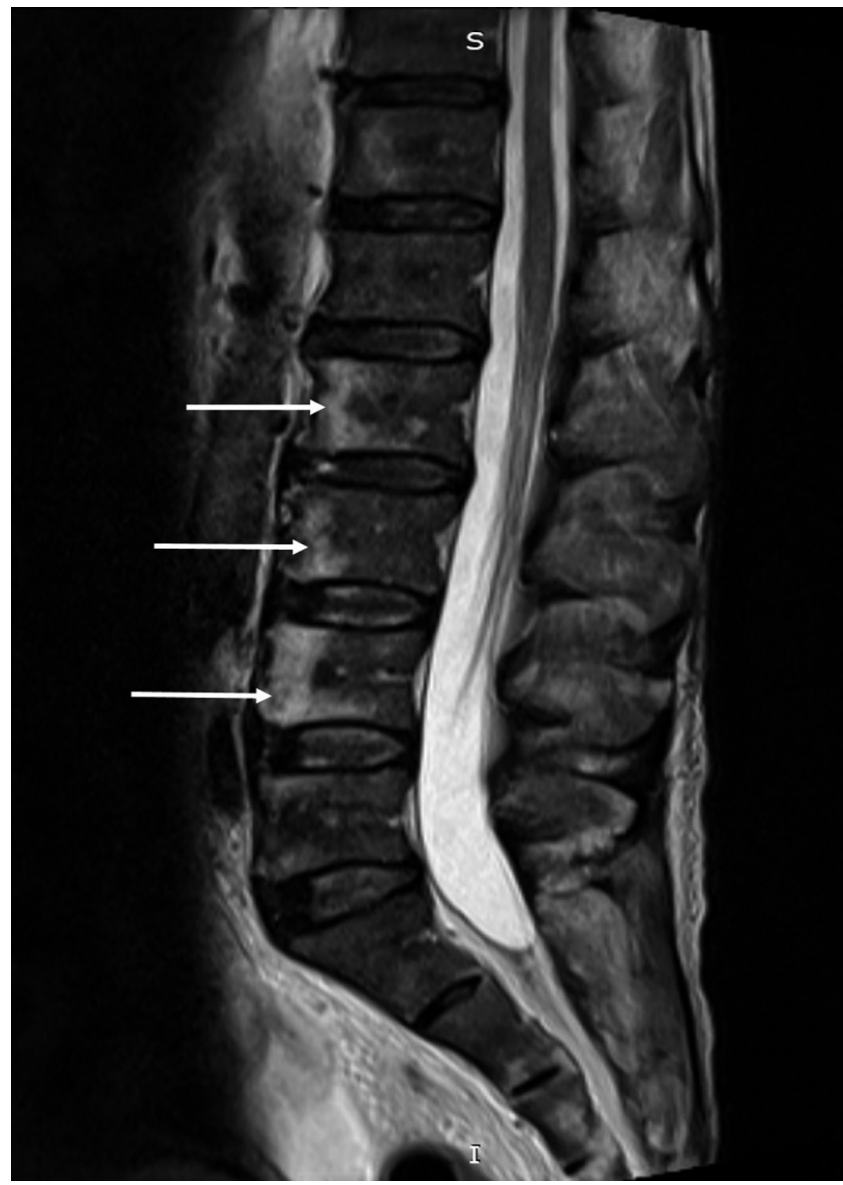

Figura 4. Resonancia magnética nuclear (RMN) de columna lumbar que evidencia lesiones focales de aspecto lítico en L2, L3 y L4 (flechas blancas).

losis, ocupando el sexto lugar (9). Los datos de mortalidad relacionados alcanzan el $2 \%$ en pacientes con tratamiento antituberculoso (10). En la literatura local no hay datos de prevalencia ni datos de morbimortalidad en el caso de la presentación de este tipo de tuberculosis extrapulmonar. La tuberculosis zoonótica causada por Mycobacterium bovis representa $<1 \%$ de las causas de tuberculosis del TGI, relacionado con productos lácteos no pasteurizados (11).

La fisiopatología detrás de la infección por el bacilo puede darse por ingesta del esputo desde un foco activo en el pulmón, diseminación hematógena o linfática y contacto directo desde un órgano adyacente. El bacilo tiene una mayor predilección por la región ileocecal y el íleon terminal debido a sus características como la estasis, abundante tejido linfoide, tasa incrementada de absorción y un contacto directo del bacilo con la mucosa (7). Adicionalmente, 
en las placas de Peyer, la presencia de las células $\alpha$, encargadas de fagocitar los agentes extraños, sirven como puerta de entrada del microorganismo (11).

La tuberculosis gastrointestinal tiene una presentación clínica larvada, bizarra e inespecífica. En un estudio realizado por Patel (12), en el que se estudiaron 69 pacientes con tuberculosis del TGI y de los cuales un $84 \%$ tenía compromiso de la válvula ileocecal, los síntomas más comunes fueron dolor abdominal (76\%), fiebre (72\%), pérdida de peso $(60 \%)$, diarrea crónica ( $28 \%)$ y sensación de masa abdominal (10\%). En algunos casos pueden existir complicaciones como la perforación intestinal, formación de fistula, obstrucción secundaria a masa (tuberculoma) o sangrado del TGI $(11,13)$. En los hallazgos macroscópicos de la tuberculosis del TGI, las principales lesiones son úlceras de la mucosa $(60 \%)$ con un componente transversal con mayor afectación al yeyuno, íleon y ciego; seguido por lesiones úlcero-hipertróficas (30\%) y, por último, las lesiones hipertróficas (10\%) con mayor afectación del íleon y del ciego (13). Los cambios histológicos son inflamación granulomatosa caseificante confluente, macrófagos epitelioides, células gigantes de Langhans y linfocitos. Sin embargo, ninguno de estos hallazgos es patognomónico de la enfermedad, por lo que se requiere de ayudas adicionales como tinciones, cultivos o pruebas moleculares (14).

Los hallazgos imagenológicos son poco sensibles, con signos indirectos como obstrucción, perforación o nódulos linfoides mesentéricos calcificados. Las técnicas con bario son útiles para demostrar las lesiones de la mucosa, constricción, un ciego deformado o una válvula ileocecal disfuncional y dilatada (13). En la tomografía puede haber un engrosamiento asimétrico de la pared intestinal con crecimiento ganglionar, estrechez en el íleon terminal, adenopatías paraaórticas y mesentéricas con extensas áreas de hipodensidad central e hipercaptación periférica (15).

Las alteraciones en los laboratorios son inespecíficas. Se encuentra leucopenia, trombocitopenia, anemia, aumento en la velocidad de sedimentación globular y proteína $\mathrm{C}$ elevada (16). En el diagnóstico o aislamiento del bacilo se tienen herramientas desde el uso de la microscopia y cultivo para micobacterias, hasta PCR. El cultivo muestra una sensibilidad alrededor del $60 \%$ con la limitante de tiempo para resultado de 4 semanas. La PCR es el estudio con mayor rendimiento para diagnóstico de tuberculosis intestinal con datos de sensibilidad alrededor del $87 \%$ y una especificidad del $96 \%$ (17) para las PCR de nuevas generaciones. Sin embargo, en un estudio realizado por Kivihya-Ndugga (18), en el que se compararon la radiografía de tórax, la tinción de Ziehl-Neelsen y la PCR para el diagnóstico de tuberculosis, se encontró una especificidad para la PCR del
$84 \%$, la cual fue menor en comparación con la microscopia con Ziehl-Neelsen, que fue del $98 \%$. Esto demuestra que el uso de la PCR depende de la prevalencia local de la enfermedad y de la costo-efectividad de la que se disponga cuando se sospeche un cuadro de tuberculosis.

Debido a lo anterior, el diagnóstico se basa en la sospecha clínica y los factores de riesgo que se pueden consignar en la anamnesis, acompañado de imágenes y resultados de laboratorio; aunque primero deben descartarse siempre los principales diferenciales como la enfermedad de Crohn, colitis ulcerosa, linfoma, amebiasis, histoplasmosis, entre otros (9). En el manejo de tuberculosis del TGI no varía la duración ni el esquema, como se propone en la forma pulmonar; incluso los tratamientos de 6 meses son igual de efectivos (11). Respecto al tratamiento en personas coinfectadas con tuberculosis y VIH, se basa dependiendo de los niveles de linfocitos CD4; de esta manera, si estos son menores a 100 000 células $/ \mu \mathrm{L}$, se debe iniciar el tratamiento antirretroviral con TARGA. Si los niveles están entre 100000 y 200000 células/ $\mu \mathrm{L}$, se podrá dar la primera fase del tratamiento antituberculoso con posterior inicio del TARGA y, si los niveles son mayores a 200000 células/ $\mu \mathrm{L}$, se podrán dar las dos fases del tratamiento antituberculoso antes del TARGA (11). El seguimiento y respuesta al tratamiento suele confirmarse por la desaparición de los síntomas a las 2 semanas de haber iniciado el esquema antituberculoso y la resolución de las lesiones visualizadas por procesos endoscópicos a los 3 meses de haber iniciado la terapia (13).

Se presenta un caso de tuberculosis ileocecal, una entidad poco frecuente cuya sospecha clínica obliga a descartar otras patologías incluso con mayor probabilidad de estar presentes en un paciente con síntomas inespecíficos, un síndrome febril prolongado y con múltiples comorbilidades como el presentado anteriormente. Además, la falta de claridad del cuadro y los resultados negativos de las herramientas diagnósticas habituales que se presentaron a lo largo del caso dificultaron el abordaje del paciente, lo que demoró el inicio del tratamiento. Se aporta a la literatura a través de este reporte de caso y consideramos que un adecuado entendimiento de esta forma de tuberculosis, así como su manejo, favorece la aproximación de futuros pacientes con esta enfermedad.

\section{Agradecimientos}

Hospital Universitario Mayor Méderi, Bogotá, Colombia.

\section{Conflictos de interés}

No hay conflicto de intereses que declarar. 


\section{REFERENCIAS}

1. MacNeil A, Glaziou P, Sismanidis C, Maloney S, Floyd K. Global Epidemiology of Tuberculosis and Progress Toward Achieving Global Targets - 2017. MMWR Morb Mortal Wkly Rep. 2019;68(11):263-266. https://doi.org/10.15585/mmwr.mm6811a3

2. Pérez MPL. Informe de evento tuberculosis, Colombia, 2017.2018;(03):21.

3. Narasimhan P, Wood J, Macintyre CR, Mathai D. Risk factors for tuberculosis. Pulm Med. 2013;2013:828939. https://doi.org/10.1155/2013/828939

4. Gupta RK, Lucas SB, Fielding KL, Lawn SD. Prevalence of tuberculosis in post-mortem studies of HIV-infected adults and children in resource-limited settings: a systematic review and meta-analysis. AIDS. 2015;29(15):1987-2002. https://doi.org/10.1097/QAD.0000000000000802

5. Peirse M, Houston A. Extrapulmonary tuberculosis. Medicine. 2017;45(12):747-52. https://doi.org/10.1016/j.mpmed.2017.09.008

6. Stewart RJ, Tsang CA, Pratt RH, Price SF, Langer AJ. Tuberculosis - United States, 2017. MMWR Morb Mortal Wkly Rep. 2018;67(11):317-323. https://doi.org/10.15585/mmwr.mm6711a2

7. Debi U, Ravisankar V, Prasad KK, Sinha SK, Sharma AK. Abdominal tuberculosis of the gastrointestinal tract: revisited. World J Gastroenterol. 2014;20(40):14831-40. https://doi.org/10.3748/wjg.v20.i40.14831

8. Ramírez-Lapausa M, Menéndez-Saldaña A, NogueradoAsensio A. Tuberculosis extrapulmonar, una revisión. Rev Esp Sanid Penit. 2015;17(1):3-11. https://doi.org/10.4321/S1575-06202015000100002

9. Zuluaga M. Tuberculosis intestinal: un diagnóstico para no olvidar. Reporte de un caso. Med U.P.B. 2015;34(2):165-170. https://doi.org/10.18566/\%20medupb.v34n2.a10

10. Cho JK, Choi YM, Lee SS, Park HK, Cha RR, Kim WS, Kim JJ, Lee JM, Kim HJ, Ha CY, Kim HJ, Kim TH, Jung WT, Lee OJ. Clinical features and outcomes of abdominal tuberculosis in southeastern Korea: 12 years of experience.
BMC Infect Dis. 2018;18(1):699.

https://doi.org/10.1186/s12879-018-3635-2

11. Donoghue HD, Holton J. Intestinal tuberculosis. Curr Opin Infect Dis. 2009;22(5):490-6. https://doi.org/10.1097/QCO.0b013e3283306712

12. Patel B, Yagnik VD. Clinical and laboratory features of intestinal tuberculosis. Clin Exp Gastroenterol. 2018; 11:97-103. https://doi.org/10.2147/CEG.S154235

13. Malikowski T, Mahmood M, Smyrk T, Raffals L, Nehra V. Tuberculosis of the gastrointestinal tract and associated viscera. J Clin Tuberc Other Mycobact Dis. 2018;12:1-8. https://doi.org/10.1016/j.jctube.2018.04.003

14. Rathi P, Gambhire P. Abdominal Tuberculosis. J Assoc Physicians India. 2016;64(2):38-47.

15. da Rocha EL, Pedrassa BC, Bormann RL, Kierszenbaum ML, Torres LR, D’Ippolito G. Abdominal tuberculosis: a radiological review with emphasis on computed tomography and magnetic resonance imaging findings. Radiol Bras. 2015;48(3):181-91. https://doi.org/10.1590/0100-3984.2013.1801

16. Pulimood AB, Amarapurkar DN, Ghoshal U, Phillip M, Pai CG, Reddy DN, Nagi B, Ramakrishna BS. Differentiation of Crohn's disease from intestinal tuberculosis in India in 2010. World J Gastroenterol. 2011;17(4):433-43. https://doi.org/10.3748/wjg.v17.i4.433

17. Gutiérrez O, Estay R, Cerda C, Capona R. Tuberculosis ileocecal: revisión de la literatura a partir de un caso clínico. Gastroenterol Latinoam. 2016;27(1):31-36.

18. Kivihya-Ndugga L, van Cleeff M, Juma E, Kimwomi J, Githui W, Oskam L, Schuitema A, van Soolingen D, Nganga L, Kibuga D, Odhiambo J, Klatser P. Comparison of PCR with the routine procedure for diagnosis of tuberculosis in a population with high prevalences of tuberculosis and human immunodeficiency virus. J Clin Microbiol. 2004;42(3):1012-5. https://doi.org/10.1128/jcm.42.3.1012-1015.2004 